\title{
ANALYSIS OF CALORIMETRIC METHOD OF MEASUREMENT OF NATURAL GAS CALORIFIC VALUE
}

\author{
Andriy Motalo, Ph.D., Vasyl Motalo, Prof., Dr.Sc \\ Gas Production Division "LvivGas Vydobuvannya", Ukraine; \\ Lviv Polytechnic National University, Ukraine
}

\begin{abstract}
The article considers the current methods of measuring the calorific value of natural gas which are valid in the upto-date gasometry. The procedure for measuring the gross and net volume-basis specific calorific value of natural gas by the calorimetric method is analyzed. It is shown that to increase the accuracy and validity of measurement results, the experiment to determine the values of gross and net volume-basis specific calorific should be performed for at least 5 samples of the investigated gas. A methodology for estimating the accuracy of measuring the gross and net volume-basis specific calorific values of natural gas by the calorimetric method by finding estimates of the uncertainty of the obtained measurement results taking into account both random and systematic influencing factors are developed. The uncertainty budgets for measuring the gross and net volumebasis-specific calorific values of natural gas have been developed for the practical implementation of the methodology. The results of experimental studies of samples of one of the natural gas fields are given and the objective values of the gross and net volumebasis specific calorific with estimates of extended uncertainty are obtained.

Key words: Natural Gas, Calorific Value of Natural Gas, Calorific Method of Measurement, Uncertainty
\end{abstract}

\section{Introduction}

The largest sphere of natural gas (NG) applying today is industrial and communal services, in which gas is used as fuel. The main index of NG quality, which determines its energy value, is the specific volumetric heat of combustion or the calorific value of gas [1-3]. It is set as the amount of heat released during the complete combustion in the air of a certain volume of gas at constant pressure, $p_{\text {comb }}, \mathrm{kPa}$ and constant temperature, $t_{\text {comb }},{ }^{\circ} \mathrm{C}$ relative to the volume of dry gas determined under standard conditions, namely the pressure $p_{\text {ref }}=101.325 \mathrm{kPa}$ and temperature $t_{\text {ref }}=20^{\circ} \mathrm{C}$ [4]. Complete combustion of gas, as well as any other fuel, is observed when there are no burning gas components or components of incomplete oxidation in gaseous combustion products. In gas analysis, there are net and gross specific volumetric heat of combustion of gas [5]. The volume-basis net specific calorific value $\left(H_{V}\right)_{N}$, $\mathrm{MJ} / \mathrm{m}^{3}$ is determined in the presence of water vapor in the combustion gas products at the temperature $t_{\text {comb }},{ }^{\circ} \mathrm{C}$, and the volume-basis gross specific calorific value $\left(H_{V}\right)_{G}, \mathrm{MJ} / \mathrm{m}^{3}$ after complete condensation of water vapor contained in the combustion gas products at the temperature $t_{\text {comb }},{ }^{\circ} \mathrm{C}$. The issue of natural gas quality has always attracted a lot of attention from specialists, as evidenced by a large number of publications [6-10]. At the same time, various aspects are analyzed, both in terms of natural gas energy value and environmental protection. The calorific value of gas as an index of its quality is especially important for the domestic sphere of NG consumption. In particular, in developed foreign countries, mutual settlements between consumers and gas suppliers are based on energy $E$, MJ of the consumed gas. According to [11], it is found as the product of the consumed volume of gas $V, \mathrm{~m}^{3}$ at its volume-basis gross specific calorific value $\left(H_{V}\right)_{G}, \mathrm{MJ} / \mathrm{m}^{3}$, i.e,
$E=V \cdot\left(H_{V}\right)_{G}, \mathrm{MJ}$, and is used to determine the value of gas consumed. Therefore, the accuracy of measuring the NG calorific value directly affects the accuracy of estimating its energy value and, accordingly, the cost of gas.

\section{Methods of Measuring the Natural Gas}

\section{Calorific Value}

Today, the values of gross $\left(H_{V}\right)_{G}, \mathrm{MJ} / \mathrm{m}^{3}$ and net $\left(H_{V}\right)_{N}, \mathrm{MJ} / \mathrm{m}^{3}$ volume-basis specific calorific value of gas according to [11] are measured by two main methods:

- by the method of indirect measurement by calculation based on the component composition and volume fractions of combustible components of the gas mixture;

- by direct measurement method or calorimetric method using a water calorimeter.

The method of indirect measurement is based on the preliminary determination of the component composition of the gas by the chromatographic method following the requirements of [12] and subsequent calculation of the gross and net volume-basis specific calorific values of gas according to the methodology described in [13]:

$$
\left(H_{V}\right)_{G}=\sum_{i=1}^{k}\left(H_{V}\right)_{G, i} \cdot C_{i} ;\left(H_{V}\right)_{N}=\sum_{i=1}^{k}\left(H_{V}\right)_{N, i} \cdot C_{i},(1)
$$

where $\left(H_{V}\right)_{G, i}$ and $\left(H_{V}\right)_{N, i}$ are respectively gross and net (inferior volume-basis specific calorific value of the $i$-th component of the gas, determined by theoretical calculations and given in [13], $\mathrm{MJ} / \mathrm{m}^{3} ; C_{i}$ is the concentration of the $i$-th gas component in the gas mixture; $k$ is the number of combustible components of the gas mixture.

The calculation method for determining the gas calorific value is easier to implement than the calorimetric one because it uses the results of chromatographic studies of the component composition of the gas, which are mandatory for gas production 
companies. However, it should be noted that the obtained measurement results are inflated compared to the results of the calorimetric method and do not reflect the actual calorific value of the test gas. Because as it does not take into account gas humidity and the presence of non-combustible components, in particular carbon dioxide, nitrogen, helium, etc. Such results may be an objective assessment of the gas calorific value only for dried and purified gas.

The calorimetric method of measuring the gas calorific value is implemented using a gas water calorimeter of continuous action [14-16]. In this case, gas mixtures are studied, which in the process of measurement do not change their component composition and physicochemical properties, in particular, humidity and the presence of non-combustible components. The advantage of the calorimetric method, despite the complexity of the measurement process, is the objectivity of the results, as it takes into account gas humidity and the presence of non-combustible components in the extracted gas. So, it can be used for continuous monitoring of the energy value of extracted gas in real-time.

Thus, according to the analysis, the calorimetric method of measuring the specific volumetric heat of GHG combustion gives more objective measurement results than the theoretical one and is more promising in modern gasometry. Therefore, the research subject of this article is the analysis of the accuracy of measuring the gas calorific value by the calorimetric method.

The analysis of the accuracy of measuring the gas calorific value by the calorimetric method has several problems due primarily to the imperfection of existing regulations governing the requirements for accuracy of measurements and presentation of measurement results. In particular, according to [16], the arithmetic mean of the results of three independent experiments is taken as the measurement result of the gas calorific value, whose permissible deviation from the average value should not exceed $\pm 0,25 \mathrm{MJ} / \mathrm{m}^{3}$, if an obtained average value is not more than $25 \mathrm{MJ} / \mathrm{m}^{3}$, and not exceed $\pm 1 \%$ if the average value is more than $25 \mathrm{MJ} / \mathrm{m}^{3}$. Therefore, in this case, it is talking only about the scattering of the results of individual experiments around the average value due to random influencing factors. It does not take into account the impact on the measurement result of systematic influencing factors, which are caused by the Type B uncertainty of the measurement results of the quantities by which the values of the gas calorific value gas are calculated. And their influence can significantly exceed the influence on the measurement result of random factors that is the obtained average value of the gas calorific value can differ significantly from its true value. It also makes it impossible to compare the results of NG studies carried out in different chemical analytical laboratories under the requirements of [15].
3. The Purpose of the Article and the Main Objectives of the Study

The purpose of the paper is to develop a method for estimating the accuracy of measuring the calorific value of natural gas by the calorimetric method and to ensure compliance with the measurement unity. To achieve the stated objective, the following tasks have been identified:

- analyzing the calorimetric method of measuring the calorific value of natural gas;

- developing the methodology for assessing the uncertainty of the measurements of the calorific value of natural gas by calorimetric method taking into account both random and systematic impact factors;

- carrying out studies of natural gas samples in the determination of calorific values and evaluation of the accuracy of the obtained results.

\section{Analysis of the Calorimetric Method of} Measuring the Calorific Value of Natural Gas

\subsection{Elements of the calorimetric measuring} process

To analyze the accuracy of measuring the calorific value of NG by the calorimetric method, first of all, it is necessary to obtain the transformation function of the calorimeter. To do this, we analyze the method of measuring the calorific value of NG using a calorimeter by [16]. The essence of the calorimetric method of determining the calorific value of NG is to measure with a gas water calorimeter the continuous action of the amount of heat released during the combustion of a certain volume of gas. At the same time, the mass of water vapor condensate formed during the complete combustion of the gas is measuring, based on which the gross, and net volume-basis specific calorific values of the test gas, are calculating.

The main functional elements of the calorimetric measuring system are:

- Gas water calorimeter;

- Gas meter;

- Aneroid or mercury barometer;

- Thermometer with a scale interval of $0.1{ }^{\circ} \mathrm{C}$;

- Timer with a scale interval of $0.1 \mathrm{~s}$ or $0.2 \mathrm{~s}$;

- Rocker table scales with a measurement range of 5 or $10 \mathrm{~kg}$ with sets of calibrated weights.

To increase the accuracy and reliability of measurement results according to [17-19], the experiment to determine the values of the gross and net volume-basis specific calorific values of $\mathrm{NG}$ is carried out for $n$ samples of the test gas, and, according to the authors, the number of samples $\mathrm{n}$ should be at least 5 . 
4.2. Measurement of the gross volume-basis specific calorific value of the test gas

The gross volume-basis specific calorific value $\left(H_{V}\right)_{G, i}, \mathrm{MJ} / \mathrm{m}^{3}$ of $i$-th test gas sample $(i=1, \ldots, n)$ under standard conditions, that is pressure $p_{\text {ref }}=101.325 \mathrm{kPa}$ and temperature $t_{\text {ref }}=20^{\circ} \mathrm{C}$ [4], is determined by the formula:

$$
\left(H_{V}\right)_{G, i}=\frac{c_{w} m_{w, i} \Delta \Theta_{w, i} f_{k, g r}}{V_{g w, i} f_{g m} K},
$$

where $c_{w}=4.187 \cdot 10^{-6} \mathrm{MJ} /\left(\mathrm{g} \cdot{ }^{\circ} \mathrm{C}\right)$ is the specific heat capacity of water; $m_{w, i}$ is the mass of water flow taken in the calorimeter for the $i$-th test gas sample, $\mathrm{g} ; \Delta \Theta_{w, i}$ is the average difference in water temperature at the outlet and inlet of the calorimeter for the $i$-th test gas sample, ${ }^{\circ} \mathrm{C} ; f_{k, g r}$ is the correction factor calorimeter readings for gross volume-basis specific calorific value, which meaning is determined in the process of the calorimeter calibration; $V_{g w, i}$ is the volume of the $i$-th test gas sample that burns in the calorimeter during water extraction, measured by the gas meter, $\mathrm{m}^{3} ; f_{g m}$ is the correction factor for gas meter readings; $K$ is the coefficient for bringing the volume of the test gas burned to standard conditions.

The value of the coefficient $K$ is calculated by the formula:

$$
K=\frac{293 \cdot\left(p_{a i r}+p_{g}-p_{w v}\right)}{\left(273+\Theta_{g}\right) \cdot 101.325},
$$

where $p_{\text {air }}$ is the barometric air pressure during the experiment, $\mathrm{kPa} ; p_{g}$ is the gas pressure in the gas meter, $\mathrm{kPa} ; p_{w v}$ is the partial pressure of water vapor in the saturated state at the gas temperature $\Theta_{g}$ in the gas meter, $\mathrm{kPa} ; \Theta_{g}$ is the gas temperature in the gas meter, ${ }^{\circ} \mathrm{C}$. The measurement result of the gross volume-basis specific calorific value of the test gas $\left(H_{V}\right)_{G}, \mathrm{MJ} / \mathrm{m}^{3}$ is defined as the arithmetic mean of the results $\left(H_{V}\right)_{G, i}(i=1, \ldots, n)$ of the series of $n$ experiments:

$$
\left(H_{V}\right)_{G}=\frac{1}{n} \sum_{i=1}^{n}\left(H_{V}\right)_{G, i} .
$$

\subsection{Measurement of the net volume-basis} specific calorific value of the test gas

To determine the net volume-basis specific calorific value $\left(H_{V}\right)_{N, i}, \mathrm{MJ} / \mathrm{m}^{3}$ of $i$-th test gas sample $(i=1, \ldots, n)$ the mass of condensate of water vapor formed during gas combustion is measured, and its value under standard conditions is calculated by the formula:

$$
\left(H_{V}\right)_{N, i}=\left(\frac{\left(H_{V}\right)_{G, i}}{f_{k, g r}}-\frac{c_{c o n} m_{c o n, i} \Delta \Theta_{w, i}}{V_{g w v, i} f_{g m} K}\right) \cdot f_{k, n t},
$$

where $\left(H_{V}\right)_{G, i}$ is the value of the gross volume-basis specific calorific value of the $i$-th test gas sample $(i=1, \ldots, n)$, calculated by the formula (2), $\mathrm{MJ} / \mathrm{m}^{3}$; $c_{\text {con }}=2.454 \cdot 10^{-3} \mathrm{MJ} /\left(\mathrm{g} \cdot{ }^{\circ} \mathrm{C}\right)$ is the specific heat of water vapor condensation at pressure $p_{\text {ref }}=101.325 \mathrm{kPa}$ and temperature $t_{r e f}=20^{\circ} \mathrm{C} ; m_{c o n, i}$ is the mass of collected condensate of water vapor for the $i$-th test gas sample, g; $V_{g w v, i}$ is the volume of the $i$-th test gas sample that burns in the calorimeter during the collection of water vapor condensate, measured by the gas meter, $\mathrm{m}^{3} ; f_{k, n t}$ is the correction factor calorimeter readings for net volumebasis specific calorific value, which meaning is determined in the process of the calorimeter calibration.

The measurement result of the net volume-basis specific calorific value of the test $\operatorname{gas}\left(H_{V}\right)_{N}, \mathrm{MJ} / \mathrm{m}^{3}$ is defined as the average value of the results $\left(H_{V}\right)_{N, i}(i=1, \ldots, n)$ of the series of $n$ experiments:

$$
\left(H_{V}\right)_{N}=\frac{1}{n} \sum_{i=1}^{n}\left(H_{V}\right)_{N, i} .
$$

\section{Estimating the Uncertainty of NG Calorific Value Measurement Results \\ 5.1. Establishment of uncertainty components of the NG calorific values}

As can be seen from the above analysis of the calorimetric method of measuring the gross $\left(H_{V}\right)_{G}$, $\mathrm{MJ} / \mathrm{m}^{3}$, and net $\left(H_{V}\right)_{N}, \mathrm{MJ} / \mathrm{m}^{3}$ volume-basis specific calorific values of the test gas, the values of which are determined by formulas (4) and (6) taking into account the results (2) and (5), are indirect measurements with multiple observations. Therefore, the estimation of the uncertainty of the measurement results of both gross and net calorific values of $\mathrm{NG}$ should be carried out according to the method of processing the results of indirect measurements [18-19] calculating namely:

- Type B combined standard uncertainties $u_{c B}\left\{\left(H_{V}\right)_{G, i}\right\}$ and $u_{c B}\left\{\left(H_{V}\right)_{N, i}\right\}$ of the results of measuring the gross $\left(H_{V}\right)_{G}$, and net $\left(H_{V}\right)_{N}$ calorific values of $i$-th test gas sample, taking into account equations (3) and (5);

- Type A standard uncertainties $u_{A}\left\{\left(H_{V}\right)_{G}\right\}$ and $u_{A}\left\{\left(H_{V}\right)_{N}\right\}$ of the results of measuring the $\left(H_{V}\right)_{G}$, and $\left(H_{V}\right)_{N}$ calorific values of the test gas, taking into account equations (4) and (6); 
- The combined standard uncertainties $u_{c}\left\{\left(H_{V}\right)_{G}\right\}$, and $u_{c}\left\{\left(H_{V}\right)_{N}\right\}$ of the results of measuring the $\left(H_{V}\right)_{G}$ $\left(H_{V}\right)_{N}$ calorific values of the test gas;

- The extended uncertainties $U_{p}\left\{\left(H_{V}\right)_{G}\right\}$ and $U_{p}\left\{\left(H_{V}\right)_{N}\right\}$ of the results of measuring the $\operatorname{gross}\left(H_{V}\right)_{G}$, and $\left(H_{V}\right)_{N}$ calorific values of the test gas for a given confidence level $p$.

\subsection{Determining of Type B combined} standard uncertainty of the measurement result of the gross volume-basis specific calorific value of $i$-th test gas sample

Type B combined standard uncertainty $u_{c B}\left\{\left(H_{V}\right)_{G, i}\right\}, \mathrm{MJ} / \mathrm{m}^{3}$ of the result of measuring the gross volume-basis specific calorific value $\left(H_{V}\right)_{G, i}$, $\mathrm{MJ} / \mathrm{m}^{3}$ of $i$-th test gas sample $(i=1, \ldots, n)$ has 7 components caused by 7 impact factors that are Type B standard uncertainties $u_{B}\left(x_{j}\right)$ of measurement results of measuring the quantities $x_{j}, j=1, \ldots, 7$ that are $c_{w}, m_{w}, \Delta \Theta_{w}, f_{k, g r}, V_{g}, f_{g m}, K$, included in the formula (3) for its calculating, namely:

- Type B standard uncertainty $u_{B}\left(c_{w}\right), \mathrm{MJ} /\left(\mathrm{g} \cdot{ }^{\circ} \mathrm{C}\right)$ of the value of specific heat capacity of water $c_{w}$;

- Type B standard uncertainty $u_{B}\left(m_{w, i}\right)$, g of the result of measuring the mass of water $m_{w, i}$ taken in the calorimeter for the $i$-th test gas sample;

- Type B combine standard uncertain$\operatorname{ty} u_{c B}\left(\Delta \Theta_{w, i}\right),{ }^{\circ} \mathrm{C}$ of the result of measuring the average difference in water temperature $\Delta \Theta_{w, i}$ at the outlet and inlet of the calorimeter for the $i$-th test gas sample;

- Type B standard uncertainty $u_{B}\left(f_{k, g r}\right)$ of the calorimeter readings correction factor value $f_{k, g r}$ for the gross volume-basis specific calorific value of test gas;

- Type B standard uncertainty $u_{B},\left(V_{g, i}\right), \mathrm{m}^{3}$ of the result of measuring the volume $V_{g w, i}$ of the $i$-th test gas sample that burns in the calorimeter during water extraction, measured by the gas meter;

- Type B standard uncertainty $u_{B}\left(f_{g m}\right)$ of the correction factor value $f_{g m}$ for gas meter readings;

- Type B combines standard uncertainty $u_{c B}(K)$ of the result of measuring the coefficient value $K$ for bringing the volume of the test gas burned to standard conditions.
In the absence of correlation between the above quantities, the Type B combined standard uncertainty $u_{c B}\left\{\left(H_{V}\right)_{G, i}\right\}, \mathrm{MJ} / \mathrm{m}^{3}$ of the result of measuring the gross volume-basis specific calorific value $\left(H_{V}\right)_{G, i}$, $\mathrm{MJ} / \mathrm{m}^{3}$ of $i$-th test gas sample $(i=1, \ldots, n)$ according to [18-19] is determined by the formula:

$$
\frac{u_{c B}\left\{\left(H_{V}\right)_{G, i}\right\}=\sqrt{C_{c_{w}}^{2} \cdot u_{B}^{2}\left(c_{w w}\right)+C_{m_{w i}}^{2} \cdot u_{B}^{2}\left(m_{w, i}\right)+C_{\Delta \theta_{w i}}^{2} \cdot u_{c B}^{2}\left(\Delta \Theta_{w, i}\right)+}}{+C_{f_{k, g}}^{2} \cdot u_{B}^{2}\left(f_{k, g r}\right)+C_{V_{s,}}^{2} \cdot u_{B}^{2}\left(V_{g, i}\right)+C_{f_{g n}}^{2} \cdot u_{B}^{2}\left(f_{g m}\right)+C_{K}^{2} \cdot u_{c B}^{2}(K)}
$$

where $C_{c_{w}}, \mathrm{MJ} /\left(\mathrm{g} \cdot{ }^{\circ} \mathrm{C}\right)$ is the sensitivity coefficient of the uncertainty $u_{B}\left(c_{w}\right) ; C_{m_{w i}}, \mathrm{MJ} /\left(\mathrm{g} \cdot \mathrm{m}^{3}\right)$ is the sensitivity coefficient of uncertainty $u_{B}\left(m_{w, i}\right) ; C_{\Delta \Theta_{w i}}, \mathrm{MJ} /\left({ }^{\circ} \mathrm{C} \cdot \mathrm{m}^{3}\right)$ is the sensitivity coefficient of the uncertainty $u_{c B}\left(\Delta \Theta_{w, i}\right) ; C_{f_{k, g r}}, \mathrm{MJ} / \mathrm{m}^{6}$ is the sensitivity coefficient of the uncertainty $u_{B}\left(f_{k, g r}\right) ; C_{V_{g, i}}, \mathrm{MJ} / \mathrm{m}^{3}$ is the sensitivity coefficient of the uncertainty $u_{B},\left(V_{g, i}\right) ; C_{f_{g m}}$, $\mathrm{MJ} / \mathrm{m}^{3}$ is the sensitivity coefficient of the uncertainty $u_{B}\left(f_{g m}\right) ; C_{K}, \mathrm{MJ} / \mathrm{m}^{3}$ is the sensitivity coefficient of the uncertainty $u_{c B}(K)$.

The budget of Type B combined standard uncertainty $u_{c B}\left\{\left(H_{V}\right)_{G, i}\right\}, \mathrm{MJ} / \mathrm{m}^{3}$ of the result of measuring the gross volume-basis specific calorific value $\left(H_{V}\right)_{G, i}$, $\mathrm{MJ} / \mathrm{m}^{3}$ of the $i$-th test gas sample $(i=1, \ldots, n)$ is given in Table. 1 .

Expressions for finding the sensitivity coefficients $C_{j}, j=1, \ldots, 7$, which are given in Table 1 , are obtained from equation (2) as partial derivatives of the measurement result of the gross volume-basis specific calorific value $\left(H_{V}\right)_{G, i}, \mathrm{MJ} / \mathrm{m}^{3}$ for each argument $x_{j}, j=1, \ldots, 7$ that is for $c_{w}, m_{w}, \Delta \Theta_{w}, f_{k, g r}, V_{g}, f_{g m}, K$ :

$$
C_{j}=\frac{\partial\left(H_{V}\right)_{G, i}}{\partial x_{j}}, j=1,2, \ldots, 7 \text {. }
$$

5.3. Determining of Type B combined standard uncertainty of the measurement result of net volumebasis-specific calorific value of $i$-th test gas sample

Type B combined standard uncertainty $u_{c B}\left\{\left(H_{V}\right)_{N, i}\right\}, \mathrm{MJ} / \mathrm{m}^{3}$ of the result of measuring the net volume-basis specific calorific value $\left(H_{V}\right)_{N, i}, \mathrm{MJ} / \mathrm{m}^{3}$ of $i$-th test gas sample $(i=1, \ldots, n)$ has 9 components caused by 7 influential factors that are Type B standard uncertainties $u_{B}\left(x_{j}\right)$ of measurement results of measuring the quantities $x_{j}, j=1, \ldots, 9$ that are $\left(H_{V}\right)_{G, i}, f_{k, g r}, c_{c o n}, m_{c o n, i}, \Delta \Theta_{w, i}, V_{g w v, i}, f_{g m}, K, f_{k, n t}$, included in the formula (5) for its calculating, namely: 
Table 1

The budget of Type B combined standard uncertainty of measurement the gross volume-basis specific calorific value of $i$-th test gas sample

\begin{tabular}{|c|c|c|c|c|}
\hline $\begin{array}{c}\text { Input } \\
\text { quantity } \\
x_{j}\end{array}$ & $\begin{array}{l}\text { Standard uncertainty } \\
\qquad u\left(x_{j}\right)\end{array}$ & $\begin{array}{l}\text { Type of evaluation, } \\
\text { probability distribution }\end{array}$ & $\begin{array}{l}\text { Sensitivity coefficient } \\
\qquad C_{j}\end{array}$ & $\begin{array}{l}\text { Contribution to the } \\
\text { combined standard } \\
\text { uncertainty } \\
\qquad\left|C_{j}\right| \cdot u\left(x_{j}\right)\end{array}$ \\
\hline $\begin{array}{c}c_{w}, \\
\mathrm{MJ} /\left(\mathrm{g} \cdot{ }^{\circ} \mathrm{C}\right)\end{array}$ & $\begin{array}{c}u_{B}\left(c_{w}\right)=\frac{q_{c_{w}}}{2 \sqrt{3}}, \\
\mathrm{MJ} /\left(\mathrm{g} \cdot{ }^{\circ} \mathrm{C}\right)\end{array}$ & $\begin{array}{l}\text { Type B, } \\
\text { rectangular }\end{array}$ & $\begin{aligned} C_{c_{w}}= & \frac{m_{w, i} \Delta \Theta_{w, i} f_{k, g r}}{V_{g w, i} f_{g m} K}, \\
& \left(\mathrm{~g} \cdot{ }^{\circ} \mathrm{C}\right) / \mathrm{m}^{3}\end{aligned}$ & $\begin{array}{c}C_{c_{w}} \cdot u_{B}\left(c_{w}\right) \\
\mathrm{MJ} / \mathrm{m}^{3}\end{array}$ \\
\hline$m_{w, i}, \mathrm{~g}$ & $u_{B}\left(m_{w, i}\right)=\frac{\Delta m_{\mathrm{w}, \mathrm{mpe}}}{\sqrt{3}}, \mathrm{~g}$ & $\begin{array}{l}\text { Type } \mathbf{B}, \\
\text { rectangular }\end{array}$ & $\begin{array}{c}C_{m_{w, i}}=\frac{c_{w} \Delta \Theta_{w, i} f_{k, g r}}{V_{g w, i} f_{g m} K}, \\
\mathrm{MJ} /\left(\mathrm{g} \cdot \mathrm{m}^{3}\right)\end{array}$ & $\begin{array}{c}C_{m_{w, i}} \cdot u_{B}\left(m_{w, i}\right) \\
\mathrm{MJ} / \mathrm{m}^{3}\end{array}$ \\
\hline$\Delta \Theta_{w, i},{ }^{\circ} \mathrm{C}$ & $u_{c B}\left(\Delta \Theta_{w, i}\right),{ }^{\circ} \mathrm{C}$ & $\begin{array}{l}\text { Combined, } \\
\text { by the methodology } \\
\text { of indirect } \\
\text { measurements, } \\
\text { normal }\end{array}$ & $\begin{array}{c}C_{\Delta \Theta_{w, i}}=\frac{c_{w} m_{w, i} f_{k, g r}}{V_{g w, i} f_{g m} K}, \\
\mathrm{MJ} /\left({ }^{\circ} \mathrm{C} \cdot \mathrm{m}^{3}\right)\end{array}$ & $\begin{array}{c}C_{\Delta \Theta_{w, i}} \cdot u_{c B}\left(\Delta \Theta_{w, i}\right) \\
\mathrm{MJ} / \mathrm{m}^{3}\end{array}$ \\
\hline$f_{k, g r}$ & $u_{B}\left(f_{k, g r}\right)=\frac{q_{f_{k, g r}}}{2 \sqrt{3}}$ & $\begin{array}{l}\text { Type } \mathbf{B}, \\
\text { rectangular }\end{array}$ & $\begin{array}{c}C_{f_{k, g r}}=\frac{c_{w} m_{w, i} \Delta \Theta_{w, i}}{V_{g w, i} f_{g m} K}, \\
\mathrm{MJ} / \mathrm{m}^{3}\end{array}$ & $\begin{array}{c}C_{f_{k, g r}} \cdot u_{B}\left(f_{k, g r}\right) \\
\mathrm{MJ} / \mathrm{m}^{3}\end{array}$ \\
\hline$V_{g, i}, \mathrm{~m}^{3}$ & $u_{B}\left(V_{g, i}\right)=\frac{\Delta V_{g m, m p e}}{\sqrt{3}}, \mathrm{~m}^{3}$ & $\begin{array}{l}\text { Type B, } \\
\text { rectangular }\end{array}$ & $\begin{array}{c}C_{V_{g w, i}}=-\frac{c_{w} m_{w, i} \Delta \Theta_{w, i} f_{k, g r}}{V_{g w, i}^{2} f_{g m} K} \\
\mathrm{MJ} / \mathrm{m}^{6}\end{array}$ & $\begin{array}{c}\left|C_{V_{g, i}}\right| \cdot u_{B}\left(V_{g, i}\right) \\
\mathrm{MJ} / \mathrm{m}^{3}\end{array}$ \\
\hline$f_{g m}$ & $u_{B}\left(f_{g m}\right)=\frac{q_{f_{g m}}}{2 \sqrt{3}}$ & $\begin{array}{l}\text { Type } \mathbf{B}, \\
\text { rectangular }\end{array}$ & $\begin{array}{c}C_{f_{g n}}=-\frac{c_{w} m_{w, i} \Delta \Theta_{w, i} f_{k, g r}}{V_{g w, i} f_{g m}^{2} K} \\
\mathrm{MJ} / \mathrm{m}^{3}\end{array}$ & $\begin{array}{c}\left|C_{f_{g m}}\right| \cdot u_{B}\left(f_{g m}\right) \\
\mathrm{MJ} / \mathrm{m}^{3}\end{array}$ \\
\hline$K$ & $u_{c B}(K)$ & $\begin{array}{l}\text { Combined, } \\
\text { by the methodology } \\
\text { of indirect } \\
\text { measurements, } \\
\text { normal }\end{array}$ & $\begin{array}{c}C_{K}=-\frac{c_{w} m_{w, i} \Delta \Theta_{w, i} f_{k, g r}}{V_{g w, i} f_{g m} K^{2}} \\
\mathrm{MJ} / \mathrm{m}^{3}\end{array}$ & $\begin{array}{c}\left|C_{K}\right| \cdot u_{c B}(K) \\
\mathrm{MJ} / \mathrm{m}^{3}\end{array}$ \\
\hline $\begin{array}{l}\text { Output } \\
\text { quantity }\end{array}$ & $\begin{array}{c}\text { Type of evaluation, } \\
\text { probability distribution }\end{array}$ & \multicolumn{3}{|c|}{ Type B combined standard uncertainty } \\
\hline $\begin{array}{l}\left(H_{V}\right)_{G, i}, \\
\mathrm{MJ} / \mathrm{m}^{3}\end{array}$ & $\begin{array}{c}\text { Combined, } \\
\text { by the methodology } \\
\text { of indirect measurements, } \\
\text { normal }\end{array}$ & \multicolumn{3}{|c|}{$\frac{u_{c B}\left\{\left(H_{V}\right)_{G, i}\right\}=\sqrt{C_{c_{w}}^{2} u_{B}^{2}\left(c_{w}\right)+C_{m_{w, i}}^{2} u_{B}^{2}\left(m_{w, i}\right)+C_{\Delta \Theta_{w, i}}^{2} u_{B}^{2}\left(\Delta \Theta_{w, i}\right)+}}{+C_{f_{k, g r}}^{2} u_{B}^{2}\left(f_{k, g r}\right)+C_{V_{g, i}}^{2} u_{B}^{2}\left(V_{g, i}\right)+C_{f_{g m}}^{2} u_{B}^{2}\left(f_{g m}\right)+C_{K}^{2} u_{B}^{2}(K)}, \mathrm{MJ} / \mathrm{m}^{3}$} \\
\hline \multicolumn{5}{|c|}{$\begin{array}{l}q_{c_{w}} \text { is the quantization interval or the unit of the least significant digit of the value of specific heat capacity of water } c_{w} \text {; } \\
\Delta m_{\mathrm{w}, \mathrm{mpe}} \text { is the maximum permissible error of scales for measuring the mass of water; } \Delta V_{g m, m p e} \text { is the maximum permissible error } \\
\text { of the gas meter; } q_{f_{k, g r}} \text { is the quantization interval or the unit of the least significant digit of the coefficient } f_{k, g r} \text { value; } q_{f_{g m}} \text { is } \\
\text { the quantization interval or the unit of the least significant digit of the coefficient } f_{g m} \text { value }\end{array}$} \\
\hline
\end{tabular}

Type B combined standard uncertainty $u_{c B}\left\{\left(H_{V}\right)_{G, i}\right\}, \mathrm{MJ} / \mathrm{m}^{3}$ of measurement of the gross volume-basis specific calorific value $\left(H_{V}\right)_{G, i}, \mathrm{MJ} / \mathrm{m}^{3}$ of $i$-th test gas sample;

- Type B standard uncertainty $u_{B}\left(f_{k, g r}\right)$ of the calorimeter readings correction factor value $f_{k, g r}$ for the gross volume-basis specific calorific value of test gas;

- Type B standard uncertainty $u_{B}\left(c_{c o n}\right)$ of the value of specific heat of water vapor condensation $c_{c o n}$;
- Type B standard uncertainty $u_{B}\left(m_{c o n, i}\right)$, g of the result of measuring the mass $m_{c o n, i}$ of collected condensate of water vapor for the $i$-th test gas sample;

- Type B combined standard uncertainty $u_{B}\left(\Delta \Theta_{w, i}\right),{ }^{\circ} \mathrm{C}$ of the result of measuring the average difference in water temperature $\Delta \Theta_{w, i}$ at the outlet and inlet of the calorimeter for the $i$-th test gas sample;

- Type B standard uncertainty $u_{B},\left(V_{g w v, i}\right), \mathrm{m}^{3}$ of the result of measuring the volume $V_{g w v, i}$ of the $i$-th test gas 
sample that burns in the calorimeter during the collection of water vapor condensate, measured by the gas meter;

- Type B standard uncertainty $u_{B}\left(f_{g m}\right)$ of the correction factor value $f_{g m}$ for gas meter readings;

- Type B combined standard uncertainty $u_{c B}(K)$ of the result of measuring of the coefficient value $K$ for bringing the volume of the test gas burned to standard conditions;

- Type B standard uncertainty $u_{B}\left(f_{k, n t}\right)$ of the calorimeter readings correction factor value $f_{k, n t}$ for the net volume-basis specific calorific value of test gas.

In the absence of correlation between the above quantities, the Type B combined standard uncertainty $u_{c B}\left\{\left(H_{V}\right)_{N, i}\right\}, \mathrm{MJ} / \mathrm{m}^{3}$ of the result of measuring the net (inferior)volume-basis specific calorific value $\left(H_{V}\right)_{N, i}$, $\mathrm{MJ} / \mathrm{m}^{3}$ of $i$-th test gas sample $(i=1, \ldots, n)$ according to $[13,14]$ is determined by the formula:

$$
\begin{aligned}
& u_{c B}\left\{\left(H_{V}\right)_{N, i}\right\}=\sqrt{C_{\left(H_{V}\right)_{G i}}^{2} \cdot u_{c B}^{2}\left\{\left(H_{V}\right)_{G, i}\right\}+C_{f_{k, g r}}^{2} \cdot u_{B}^{2}\left(f_{k, g r}\right)+} \\
& +\frac{C_{c_{c o n}}^{2} \cdot u_{B}^{2}\left(c_{c o n}\right)+C_{m_{c o n}, i}^{2} \cdot u_{B}^{2}\left(m_{c o n, i}\right)+C_{\Delta \Theta_{w, i}}^{2} \cdot u_{c B}^{2}\left(\Delta \Theta_{w, i}\right)+C_{V_{g w w i}}^{2} \cdot u_{B}^{2}\left(V_{g w, i}\right)+}{+C_{f_{g n}}^{2} \cdot u_{B}^{2}\left(f_{g m}\right)+C_{K}^{2} \cdot u_{c B}^{2}(K)+C_{f_{k, n t}^{2}}^{2} \cdot u_{B}^{2}\left(f_{k, n t}\right)},
\end{aligned}
$$

where $C_{\left(H_{V}\right)_{G, i}}$ is the sensitivity coefficient of the uncertainty $u_{c B}\left\{\left(H_{V}\right)_{G, i}\right\} ; C_{f_{k, g r}}, \mathrm{MJ} / \mathrm{m}^{3}$ is the sensitivity coefficient of $u_{B}\left(f_{k, g r}\right) ; C_{c_{c o n}}, \mathrm{~g} / \mathrm{m}^{3}$ is the sensiti- vity coefficient of $u_{B}\left(c_{c o n}\right) ; C_{m_{c o n} i}, \mathrm{MJ} /\left(\mathrm{g} \cdot{ }^{\circ} \mathrm{C} \cdot \mathrm{m}^{3}\right)$ is the sensitivity coefficient of $u_{B}\left(m_{c o n, i}\right) ; C_{\Delta \Theta_{w, i}}, \mathrm{MJ} /\left({ }^{\circ} \mathrm{C} \cdot \mathrm{m}^{3}\right)$ is the sensitivity coefficient of $u_{c B}\left(\Delta \Theta_{w, i}\right) ; C_{V_{g v v, i}}$, $\mathrm{MJ} /\left({ }^{\circ} \mathrm{C} \cdot \mathrm{m}^{6}\right.$ is the sensitivity coefficient of $u_{B}\left(V_{g w v, i}\right)$; $C_{f_{g m}}, \mathrm{MJ} /\left({ }^{\circ} \mathrm{C} \cdot \mathrm{m}^{3}\right)$ is the sensitivity coefficient of $u_{B}\left(f_{g m}\right) ; C_{K}, \mathrm{MJ} /\left({ }^{\circ} \mathrm{C} \cdot \mathrm{m}^{3}\right)$ is the sensitivity coefficient of $u_{c B}(K) ; C_{f_{k, n t}}, \mathrm{MJ} / \mathrm{m}^{3}$ is the sensitivity coefficient of $u_{B}\left(f_{k, n t}\right)$.

The budget of Type B combined standard uncertainty $u_{c B}\left\{\left(H_{V}\right)_{N, i}\right\}, \mathrm{MJ} / \mathrm{m}^{3}$ of the result of measuring the net (inferior) volume-basis-specific calorific value $\left(H_{V}\right)_{N, i}, \mathrm{MJ} / \mathrm{m}^{3}$ of $i$-th test gas sample $(i=1, \ldots, n)$ is given in Table 2 .

Expressions for finding the sensitivity coefficients $C_{j}, j=1, \ldots, 9$, which are given in Table 2 , are obtained from equation (5) as partial derivatives of the measurement result of the net volume-basis specific calorific value $\left(H_{V}\right)_{N, i}, \mathrm{MJ} / \mathrm{m}^{3}$ for each argument $x_{j}, j=1, \ldots, 9$, that is for

$$
\begin{gathered}
\left(H_{V}\right)_{G, i}, f_{k, g r}, c_{c o n}, m_{c o n, i}, \Delta \Theta_{w, i}, V_{g w v, i}, f_{g m}, K, f_{k, n t}: \\
C_{j}=\frac{\partial\left(H_{V}\right)_{N, i}}{\partial x_{j}}, j=1, \ldots, 9
\end{gathered}
$$

\begin{tabular}{|c|c|c|c|c|}
\hline $\begin{array}{c}\text { Input } \\
\text { quantity } \\
x_{j}\end{array}$ & $\begin{array}{l}\text { Standard uncertainty } \\
\qquad u\left(x_{j}\right)\end{array}$ & $\begin{array}{l}\text { Type of evaluation, } \\
\text { probability } \\
\text { distribution }\end{array}$ & $\begin{array}{l}\text { Sensitivity coefficient } \\
\qquad C_{j}\end{array}$ & $\begin{array}{l}\text { Contribution to the } \\
\text { combined standard } \\
\text { uncertainty }\left|C_{j}\right| \cdot u\left(x_{j}\right)\end{array}$ \\
\hline 1 & 2 & 3 & 4 & 5 \\
\hline $\begin{array}{l}\left(H_{V}\right)_{G, i}, \\
\mathrm{MJ} / \mathrm{m}^{3}\end{array}$ & $\begin{array}{c}u_{c B}\left\{\left(H_{V}\right)_{G, i}\right\} \\
\mathrm{MJ} / \mathrm{m}^{3}\end{array}$ & $\begin{array}{c}\text { Combined, } \\
\text { by the methodology } \\
\text { of indirect } \\
\text { measurements, } \\
\text { normal }\end{array}$ & $C_{\left(H_{V}\right)_{G, i}}=\frac{f_{k, n t}}{f_{k, g r}}$ & $\begin{array}{c}C_{\left(H_{V}\right)_{G, i}} \cdot u_{c B}\left\{\left(H_{V}\right)_{G, i}\right\} \\
\mathrm{MJ} / \mathrm{m}^{3}\end{array}$ \\
\hline$f_{k, g r}$ & $u_{B}\left(f_{k, g r}\right)=\frac{q_{f_{k, g r}}}{2 \sqrt{3}}$ & $\begin{array}{l}\text { Type } \mathbf{B}, \\
\text { rectangular }\end{array}$ & $\begin{array}{c}C_{f_{k, g r}}=-\frac{\left(H_{V}\right)_{G, i} \cdot f_{k, n t}}{f_{k, g r}^{2}} \\
\mathrm{MJ} / \mathrm{m}^{3}\end{array}$ & $\begin{array}{c}\left|C_{f_{k, g r}}\right| \cdot u_{B}\left(f_{k, g r}\right) \\
\mathrm{MJ} / \mathrm{m}^{3}\end{array}$ \\
\hline $\begin{array}{c}c_{c o n}, \\
\mathrm{MJ} /\left(\mathrm{g} \cdot{ }^{\circ} \mathrm{C}\right)\end{array}$ & $\begin{array}{c}u_{B}\left(c_{c o n}\right)=\frac{q_{c_{c o n}}}{2 \sqrt{3}} \\
\mathrm{MJ} /\left(\mathrm{g} \cdot{ }^{\circ} \mathrm{C}\right)\end{array}$ & $\begin{array}{l}\text { Type } \mathbf{B} \text {, } \\
\text { rectangular }\end{array}$ & $\begin{array}{c}\mathrm{C}_{c_{c o n}}=-\frac{m_{c o n, i} \Delta \Theta_{w, i} f_{k, n t}}{V_{g w v, i} f_{g m} K}, \\
\left(\mathrm{~g} \cdot{ }^{\circ} \mathrm{C}\right) / \mathrm{m}^{3}\end{array}$ & $\begin{array}{c}\left|\mathrm{C}_{c_{c o n}}\right| \cdot u_{B}\left(c_{c o n}\right) \\
\mathrm{MJ} / \mathrm{m}^{3}\end{array}$ \\
\hline$m_{c o n, i}, \mathrm{~g}$ & $u_{B}\left(m_{c o n, i}\right)=\frac{\Delta m_{w v, m p e}}{\sqrt{3}} \Gamma$ & $\begin{array}{l}\text { Type } \mathbf{B}, \\
\text { rectangular }\end{array}$ & $\begin{array}{c}C_{m_{c o n, i}}=-\frac{c_{c o n} \Delta \Theta_{w, i} f_{k, n t}}{V_{g w v, i} f_{g m} K}, \\
\mathrm{MJ} /\left(\mathrm{g} \cdot \mathrm{m}^{3}\right)\end{array}$ & $\begin{array}{c}\left|C_{m_{c o n, i} \mid}\right| \cdot u_{B}\left(m_{c o n, i}\right) \\
\mathrm{MJ} / \mathrm{m}^{3}\end{array}$ \\
\hline
\end{tabular}

The budget of Type B combined standard uncertainty of measurement the net volume-basis specific calorific value of $i$-th test gas sample 
Continuation of Table 2

\begin{tabular}{|c|c|c|c|c|}
\hline 1 & 2 & 3 & 4 & 5 \\
\hline$\Delta \Theta_{w, i},{ }^{\circ} \mathrm{C}$ & $u_{c B}\left(\Delta \Theta_{w, i}\right),{ }^{\circ} \mathrm{C}$ & $\begin{array}{l}\text { Combined, } \\
\text { by the methodology } \\
\text { of indirect } \\
\text { measurements, } \\
\text { normal }\end{array}$ & $\begin{array}{c}C_{\Delta \Theta_{w, i}}=-\frac{c_{c o n} m_{c o n, i} f_{k, n t}}{V_{g w v, i} f_{g m} K}, \\
\mathrm{MJ} /\left({ }^{\circ} \mathrm{C} \cdot \mathrm{m}^{3}\right)\end{array}$ & $\begin{array}{c}\left|C_{\Delta \Theta_{w, i}}\right| \cdot u_{c B}\left(\Delta \Theta_{w, i}\right) \\
\mathrm{MJ} / \mathrm{m}^{3}\end{array}$ \\
\hline$V_{g w v, i}, \mathrm{M}^{3}$ & $\begin{array}{c}u_{B}\left(V_{g w v, i}\right)=\frac{\Delta V_{g m, m p e}}{\sqrt{3}} \\
\mathrm{~m}^{3}\end{array}$ & $\begin{array}{l}\text { Type B, } \\
\text { rectangular }\end{array}$ & $C_{V_{g w, i}}=\frac{c_{c o n} m_{c o n, i} \Delta \Theta_{w, i} f_{k, n t}}{V_{g w v, \mathrm{i}}^{2} f_{g m} K}, \mathrm{MJ} / \mathrm{m}^{6}$ & $\begin{array}{c}C_{V_{g w v, i}} \cdot u_{B}\left(V_{\mathrm{gwv}, i}\right) \\
\mathrm{MJ} / \mathrm{m}^{3}\end{array}$ \\
\hline$f_{g m}$ & $u_{B}\left(f_{g m}\right)=\frac{q_{f_{g m}}}{2 \sqrt{3}}$ & $\begin{array}{l}\text { Type B, } \\
\text { rectangular }\end{array}$ & $\begin{array}{c}C_{f_{g m}}=\frac{c_{c o n} m_{c o n, i} \Delta \Theta_{w, i} f_{k, n t}}{V_{g w v, i} f_{g m}^{2} K}, \\
\mathrm{MJ} / \mathrm{m}^{3}\end{array}$ & $\begin{array}{c}C_{f_{g m}} \cdot u_{B}\left(f_{g m}\right) \\
\mathrm{MJ} / \mathrm{m}^{3}\end{array}$ \\
\hline$K$ & $u_{c B}(K)$ & $\begin{array}{l}\text { Combined, } \\
\text { by the methodology } \\
\text { of indirect } \\
\text { measurements, } \\
\text { normal }\end{array}$ & $\begin{array}{c}C_{K}=\frac{c_{c o n} m_{c o n, i} \Delta \Theta_{w, i} f_{k, n t}}{V_{g w v, i} f_{g m} K^{2}} \\
\mathrm{MJ} / \mathrm{m}^{3}\end{array}$ & $\begin{array}{c}C_{K} \cdot u_{c B}(K) \\
\mathrm{MJ} / \mathrm{m}^{3}\end{array}$ \\
\hline$f_{k, n t}$ & $u_{B}\left(f_{k, n t}\right)=\frac{q_{f_{k, n t}}}{2 \sqrt{3}}$ & $\begin{array}{l}\text { Type B, } \\
\text { rectangular }\end{array}$ & $\begin{array}{c}C_{f_{k, n t}}=\frac{\left(H_{V}\right)_{G, i}}{f_{k, g r}}-\frac{c_{c o n} m_{c o n, i} \Delta \Theta_{w, i}}{V_{g w v, i} f_{g m} K} \\
\mathrm{MJ} / \mathrm{m}^{3}\end{array}$ & $\begin{array}{c}C_{f_{k, n t}} \cdot u_{B}\left(f_{k, n t}\right) \\
\mathrm{MJ} / \mathrm{m}^{3}\end{array}$ \\
\hline $\begin{array}{l}\text { Output } \\
\text { quantity }\end{array}$ & $\begin{array}{c}\text { Type of evaluation, } \\
\text { probability distribution }\end{array}$ & \multicolumn{3}{|c|}{ Type B combined standard uncertainty } \\
\hline $\begin{array}{l}\left(H_{V}\right)_{N, i} \\
\mathrm{MJ} / \mathrm{m}^{3}\end{array}$ & $\begin{array}{l}\text { Combined, } \\
\text { by the methodology } \\
\text { of indirect } \\
\text { measurements, } \\
\text { normal }\end{array}$ & \multicolumn{3}{|c|}{$\begin{array}{c}u_{c B}\left\{\left(H_{V}\right)_{\mathrm{N}, i}\right\}=\sqrt{C_{\left(H_{V}\right)_{G, i}}^{2} \cdot u_{c B}^{2}\left\{\left(H_{V}\right)_{G, i}\right\}+C_{f_{k, g r}}^{2} \cdot u_{B}^{2}\left(f_{k, g r}\right)+C_{c_{c o n}}^{2} \cdot u_{B}^{2}\left(c_{c o n}\right)+C_{m_{c o n, i}}^{2} \cdot u_{B}^{2}\left(m_{c o}\right.} \\
+\overline{C_{\Delta \Theta_{w, i}}^{2} \cdot u_{c B}^{2}\left(\Delta \Theta_{w, i}\right)+C_{V_{g w v}, i}^{2} \cdot u_{B}^{2}\left(V_{g w v, i}\right)+C_{f_{g m}}^{2} \cdot u_{B}^{2}\left(f_{g m}\right)+C_{K}^{2} \cdot u_{c B}^{2}(K)+C_{f_{k, n t}}^{2} \cdot u_{B}^{2}\left(f_{k, n t}\right)}, \\
\mathrm{MJ} / \mathrm{m}^{3}\end{array}$} \\
\hline \multicolumn{5}{|c|}{$\begin{array}{l}q_{f_{k, g}} \text { is the quantization interval or the unit of the least significant digit of the coefficient } f_{k, g r} \text { value; } q_{c_{c o n}} \text { is the quantization } \\
\text { interval or the unit of the least significant digit of water vapor condensation } c_{c o n} ; \Delta m_{\mathrm{wv}, \mathrm{mpe}} \text { is the maximum permissible error of } \\
\text { scales for measuring the mass of water vapor; } \Delta V_{g m, m p e} \text { is the maximum permissible error of the gas meter; } q_{f_{g m}} \text { is the } \\
\text { quantization interval or the unit of the least significant digit of the coefficient } f_{g m} \text { value; } q_{f_{k, n t}} \text { is the quantization interval or the } \\
\text { unit of the least significant digit of the coefficient } f_{k, n t} \text { value. }\end{array}$} \\
\hline
\end{tabular}

\subsection{Determining estimates of the uncertainty} of the measurement results of the gross and net volume-basis specific calorific values of the test gas

5.4.1. Determining type A standard uncertainties of the results of measuring the gross, and net calorific values of the test gas. As mentioned above, to increase the accuracy and validity of the measurement results of the gross $\left(H_{V}\right)_{G}, \mathrm{MJ} / \mathrm{m}^{3}$, and net $\left(H_{V}\right)_{N}, \mathrm{MJ} / \mathrm{m}^{3}$ volumebasis specific calorific values of $\mathrm{NG}$, the experiment is performed for $n$ samples of the test gas. Their meanings are found as the average values by formulas (4) and (6) of the $\left(H_{V}\right)_{G, i}, \mathrm{MJ} / \mathrm{m}^{3}$ and $\left(H_{V}\right)_{N, i}, \mathrm{MJ} / \mathrm{m}^{3}$ measurement results for $i$-th test gas sample $(i=1, \ldots, n)$. Respectively, the Type A standard uncertainties $u_{A}\left\{\left(H_{V}\right)_{G}\right\}, \mathrm{MJ} / \mathrm{m}^{3}$ and $u_{A}\left\{\left(H_{V}\right)_{N}\right\}, \mathrm{MJ} / \mathrm{m}^{3}$ of the results of measuring the gross $\left(H_{V}\right)_{G}$, and net $\left(H_{V}\right)_{N}$ calorific values of the test gas, taking into account equations (4) and (6) are found by such formulas:

$$
u_{A}\left\{\left(H_{V}\right)_{G}\right\}=\frac{S_{\left(H_{V}\right)_{G}}}{\sqrt{n}} \text {, and } u_{A}\left\{\left(H_{V}\right)_{N}\right\}=\frac{S_{\left(H_{V}\right)_{N}}}{\sqrt{n}} \text {, }
$$

here $s_{\left(H_{V}\right)_{G}}$ and $s_{\left(H_{V}\right)_{N}}$ are estimates of standard deviations of individual values $\left(H_{V}\right)_{G, i}$ and $\left(H_{V}\right)_{N, i}$, accordingly, from the average values $\left(H_{V}\right)_{G}$ and $\left(H_{V}\right)_{N}$, that are found by formulas (4) and (6), which are equal to:

$$
\begin{aligned}
& s_{\left(H_{V}\right)_{G}}=\sqrt{\frac{1}{n-1} \sum_{i=1}^{n}\left\{\left(H_{V}\right)_{G, i}-\left(H_{V}\right)_{G}\right\}^{2}}, \\
& \text { and } s_{\left(H_{V}\right)_{N}}=\sqrt{\frac{1}{n-1} \sum_{i=1}^{n}\left\{\left(H_{V}\right)_{N, i}-\left(H_{V}\right)_{N}\right\}^{2}} .
\end{aligned}
$$

According to [11], the number of experiments equals $n=3$. However, to obtain reliable measurement results $\left(H_{V}\right)_{G}$, and $\left(H_{V}\right)_{N}$, it is advisable to perform the study at least for 5 gas samples. 
5.4.2. Determining the combined standard uncertainties of the results of measuring the gross and net calorific values of the test gas. Since the measurements of both of the gross $\left(H_{V}\right)_{G}, \mathrm{MJ} / \mathrm{m}^{3}$, and net $\left(H_{V}\right)_{N}, \mathrm{MJ} / \mathrm{m}^{3}$ volume-basis specific calorific values of the $i$-th test gas sample $(i=1, \ldots, n)$ are carried out by the same measuring instruments, and under the same conditions, the measurements are performed with the same accuracy. Therefore, it can be stated that Type B combined standard uncertainties $u_{c B}\left\{\left(H_{V}\right)_{G}\right\}, \mathrm{MJ} / \mathrm{m}^{3}$ and $u_{c B}\left\{\left(H_{V}\right)_{N}\right\}, \mathrm{MJ} / \mathrm{m}^{3}$ of the measurement results of the gross $\left(H_{V}\right)_{G}, \mathrm{MJ} / \mathrm{m}^{3}$, and net $\left(H_{V}\right)_{N}, \mathrm{MJ} / \mathrm{m}^{3}$ volume-basis specific calorific values of the test gas are equal, respectively, to the Type $\mathrm{B}$ combined standard uncertainties $u_{c B}\left\{\left(H_{V}\right)_{G, i}\right\}, \mathrm{MJ} / \mathrm{m}^{3}$ and $u_{c B}\left\{\left(H_{V}\right)_{N, i}\right\}$, $\mathrm{MJ} / \mathrm{m}^{3}$ of the measurement results of the gross $\left(H_{V}\right)_{G, i}$, $\mathrm{MJ} / \mathrm{m}^{3}$, and net $\left(H_{V}\right)_{N, i}, \mathrm{MJ} / \mathrm{m}^{3}$ volume-basis specific calorific values the $i$-th test gas sample, that is:

$$
\begin{gathered}
u_{c B}\left\{\left(H_{V}\right)_{G}\right\}=u_{c B}\left\{\left(H_{V}\right)_{G, i}\right\}, \\
\text { and } u_{c B}\left\{\left(H_{V}\right)_{N}\right\}=u_{c B}\left\{\left(H_{V}\right)_{N, i}\right\} .
\end{gathered}
$$

Then, the estimates of the combined standard uncertainties $u_{c}\left\{\left(H_{V}\right)_{G}\right\}, \quad \mathrm{MJ} / \mathrm{m}^{3}$ and $u_{c}\left\{\left(H_{V}\right)_{N}\right\}$, $\mathrm{MJ} / \mathrm{m}^{3}$ of the measurement results of the gross $\left(H_{V}\right)_{G}$, $\mathrm{MJ} / \mathrm{m}^{3}$, and net $\left(H_{V}\right)_{N}, \mathrm{MJ} / \mathrm{m}^{3}$ volume-basis specific calorific values of the test gas according to [18-19] are defined as the square root of the sum of squares of the found values of Type A standard uncertainties $u_{A}\left\{\left(H_{V}\right)_{G}\right\}$ and $u_{A}\left\{\left(H_{V}\right)_{N}\right\}$, and Type B combined standard uncertainties $u_{c B}\left\{\left(H_{V}\right)_{G, i}\right\}$ and $u_{c B}\left\{\left(H_{V}\right)_{N, i}\right\}$ by the formulas:

$$
\begin{array}{r}
u_{c}\left\{\left(H_{V}\right)_{G}\right\}=\sqrt{u_{A}^{2}\left\{\left(H_{V}\right)_{G}\right\}+u_{c B}^{2}\left\{\left(H_{V}\right)_{G, i}\right\}}, \\
\text { and } u_{c}\left\{\left(H_{V}\right)_{N}\right\}=\sqrt{u_{A}^{2}\left\{\left(H_{V}\right)_{N}\right\}+u_{c B}^{2}\left\{\left(H_{V}\right)_{N, i}\right\}} .
\end{array}
$$

\subsubsection{Determination of the extended uncertainties} of the results of measuring the gross and net calorific values of the test gas. The extended uncertainties, $U_{p}\left\{\left(H_{V}\right)_{G}\right\}, \mathrm{MJ} / \mathrm{m}^{3}$ and $U_{p}\left\{\left(H_{V}\right)_{N}\right\}, \mathrm{MJ} / \mathrm{m}^{3}$ of the results of measuring the gross $\left(H_{V}\right)_{G}$ and net $\left(H_{V}\right)_{N}$ calorific values of the test gas for a given confidence level $p$ are calculated by the formulas:

$$
\begin{aligned}
& U_{p}\left\{\left(H_{V}\right)_{G}\right\}=k_{p} \cdot u_{c}\left\{\left(H_{V}\right)_{G}\right\}, \\
& \quad \text { and } U_{p}\left\{\left(H_{V}\right)_{N}\right\}=k_{p} \cdot u_{c}\left\{\left(H_{V}\right)_{N}\right\},
\end{aligned}
$$

where $k_{p}$ is a coverage factor, the value of which depends on the level of confidence $p$ and the density of probability distribution of the measured values the gross $\left(H_{V}\right)_{G}$ and net $\left(H_{V}\right)_{N}$ volume-basis-specific calorific values of the test gas; $u_{c}\left\{\left(H_{V}\right)_{G}\right\}$ and $u_{c}\left\{\left(H_{V}\right)_{N}\right\}$ are the combined standard uncertainties of the measured values the gross $\left(H_{V}\right)_{G}$ and net $\left(H_{V}\right)_{N}$ volume-basis specific calorific values of the test gas which is calculated by the formula (14).

The value of the coverage factor $k_{p}$, in general, is defined as $k_{p}=t_{p}\left(v_{\text {eff }}\right)$, where $t_{p}\left(v_{\text {eff }}\right)$ is the Student's distribution or $t$-distribution quantile, determined by the corresponding effective degrees of freedom $v_{\text {eff }}$ and the level of confidence $p$ [18]. The effective degrees of freedom $v_{\text {eff }}$ of the combined standard uncertainty $u_{c}\left\{\left(H_{V}\right)_{G}\right\}$, which contains Type A $u_{A}\left\{\left(H_{V}\right)_{G}\right\}$ and Type B $u_{c B}\left\{\left(H_{V}\right)_{G}\right\}$ components, provided that all components of Type B combined uncertainty $u_{c B}\left\{\left(H_{V}\right)_{G}\right\}$ is calculated by rectangular distributions, that is $v_{\text {eff }, B}=\infty$, can be calculated by the corresponding Welch-Satterthwaite formula:

$$
v_{\text {eff }}=v_{e f f, A} \cdot\left(1+\frac{u_{c B}^{2}\left\{\left(H_{V}\right)_{G}\right\}}{u_{A}^{2}\left\{\left(H_{V}\right)_{G}\right\}}\right)^{2},
$$

where $v_{e f f, A}$ are the effective degrees of freedom of the component uncertainty $u_{A}\left\{\left(H_{V}\right)_{G}\right\}$ found by Type A evaluation, which in this case is equal to $v_{\text {eff }, A}=n-1$, where $n$ is the number of experiments.

\section{Studies of Natural Gas Samples by the Calorimetric Method}

The authors carried out the study of 5 samples of natural gas in the analytical laboratory of the Gas Production Division LvivGasVydobuvannya to determine its gross $\left(H_{V}\right)_{G}, \mathrm{MJ} / \mathrm{m}^{3}$ and net $\left(H_{V}\right)_{N}$, $\mathrm{MJ} / \mathrm{m}^{3}$ volume-basis-specific calorific values by the calorimetric method. The analysis of the accuracy of the obtained measurement results by estimating their uncertainty was also performed. The results of processing the studies are given in Tables 3-4.

After processing the experimental data, the following result of measuring the gross volume-basis specific calorific value of the studied natural gas was obtained:

$$
\begin{gathered}
\left(H_{V}\right)_{G}=(38.35 \pm 0.25) \mathrm{MJ} / \mathrm{m}^{3} ; U_{p}\left\{\left(H_{V}\right)_{G}\right\}= \\
=0.25 \mathrm{MJ} / \mathrm{m}^{3} ; p=0.95 ; k_{p}=1.96
\end{gathered}
$$


Table 3

The results of measuring the gross volume-basis specific calorific value of the test gas by the calorimetric method

\begin{tabular}{|c|l|c|c|c|}
\hline № & \multicolumn{1}{|c|}{ Name, symbol, and dimension of the input quantity } & \multicolumn{1}{|c|}{$\begin{array}{c}\text { The numeric value } \\
\text { of the input quantity } \\
x_{j}, j=1, ., 7\end{array}$} & $\begin{array}{c}\text { Maximum } \\
\text { permissible error } \\
\Delta x_{j, m p e}\end{array}$ & $\begin{array}{c}\text { Standard } \\
\text { uncertainty } \\
u_{B}\left(x_{j}\right)\end{array}$ \\
\hline 1 & Specific heat capacity of water $c_{w}, \mathrm{MJ} /\left(\mathrm{g} \cdot{ }^{\circ} \mathrm{C}\right)$ & $4.187 \cdot 10^{-6}$ & $\pm 0.43 \cdot 10^{-7}$ & $0.234 \cdot 10^{-7}$ \\
\hline 2 & Mass of water flow $m_{w}, \mathrm{~g}$ & 3500 & \pm 1.00 & 0.58 \\
\hline 3 & $\begin{array}{l}\text { The average difference in water temperature at the outlet } \\
\text { and inlet of the calorimeter } \Delta \Theta_{w},{ }^{\circ} \mathrm{C}\end{array}$ & 10.35 & \pm 0.12 & $1.16 \cdot 10^{-3}$ \\
\hline 4 & $\begin{array}{l}\text { Correction factor for calorimeter readings during the } \\
\text { measurement }\left(H_{V}\right)_{G}, f_{k, g r}\end{array}$ & 1.0061 & \pm 0.020 & $0.010^{-3}$ \\
\hline 5 & The volume of the test gas burned $V_{g w}, \mathrm{~m}^{3}$ & 4.000 & $\pm 1.0 \cdot 10^{-3}$ & $0.58 \cdot 10^{-3}$ \\
\hline 6 & Correction factor for gas meter readings $f_{g m}$ & 1.004 & $\pm 1.0 \cdot 10^{-3}$ & $0.58 \cdot 10^{-3}$ \\
\hline 7 & $\begin{array}{l}\text { The coefficient for bringing the volume of the test gas } \\
\text { burned to standard conditions } K\end{array}$ & 1.003 & & \\
\hline
\end{tabular}

Note. The table shows the average values of $m_{w}, \mathrm{~g}, \Delta \Theta_{w},{ }^{\circ} \mathrm{C}$ and $, V_{g w}, \mathrm{~m}^{3}$, obtained from the results of the study of 5 test gas samples.

Table 4

\section{The results of measuring the net volume-basis specific calorific value of the test gas by the calorimetric method}

\begin{tabular}{|c|c|c|c|c|}
\hline № & $\begin{array}{l}\text { Name, symbol, and dimension of the input quantity } \\
\qquad x_{j}, j=1, \ldots, 9\end{array}$ & $\begin{array}{l}\text { The numeric value } \\
\text { of the input quantity } \\
x_{j}\end{array}$ & $\begin{array}{l}\text { Maximum } \\
\text { permissible error } \\
\Delta x_{j, m p e}\end{array}$ & $\begin{array}{l}\text { Standard } \\
\text { uncertainty } \\
u_{B}\left(x_{j}\right)\end{array}$ \\
\hline 1 & $\begin{array}{l}\text { Gross volume-basis specific calorific value of the test } \\
\text { gas }\left(H_{V}\right)_{G}, \mathrm{MJ} / \mathrm{m}^{3}\end{array}$ & $38 ., 35$ & \pm 0.43 & 0.25 \\
\hline 2 & $\begin{array}{l}\text { Correction factor for calorimeter readings during the } \\
\text { measurement }\left(H_{V}\right)_{G}, f_{k, g r}\end{array}$ & 1.0061 & $\pm 2.0 \cdot 10^{-3}$ & $1.16 \cdot 10^{-3}$ \\
\hline 3 & $\begin{array}{l}\text { The specific heat of water vapor condensation } c_{c o n} \text {, } \\
\mathrm{MJ} /\left(\mathrm{g} \cdot{ }^{\circ} \mathrm{C}\right)\end{array}$ & $2.454 \cdot 10^{-3}$ & $\pm 0.25 \cdot 10^{-4}$ & $0.145 \cdot 10^{-4}$ \\
\hline 4 & $\begin{array}{l}\text { The mass of collected condensate of water vapor } m_{c o n} \text {, } \\
\mathrm{g}\end{array}$ & 60.50 & \pm 1.00 & 0.58 \\
\hline 5 & $\begin{array}{l}\text { The average difference in water temperature at the } \\
\text { outlet and inlet of the calorimeter } \Delta \Theta_{w},{ }^{\circ} \mathrm{C}\end{array}$ & 10.35 & \pm 0.12 & 0.07 \\
\hline 6 & $\begin{array}{l}\text { The volume of the test gas that burns in the calorimeter } \\
\text { during the collection of water vapor condensate } V_{g w v} \text {, } \\
\mathrm{m}^{3}\end{array}$ & 40.500 & \pm 0.020 & 0.0115 \\
\hline 7 & Correction factor for gas meter readings $f_{g m}$ & 1.004 & $\pm 1.0 \cdot 10^{-3}$ & $0.58 \cdot 10^{-3}$ \\
\hline 8 & $\begin{array}{l}\text { The coefficient for bringing the volume of the test gas } \\
\text { burned to standard conditions } K\end{array}$ & 1.003 & $\pm 1.0 \cdot 10^{-3}$ & $0.58 \cdot 10^{-3}$ \\
\hline 9 & $\begin{array}{l}\text { Correction factor for calorimeter readings during the } \\
\text { measurement }\left(H_{V}\right)_{N}, f_{k, n t}\end{array}$ & 1.0068 & $\pm 2.0 \cdot 10^{-3}$ & $1.16 \cdot 10^{-3}$ \\
\hline
\end{tabular}

Note. The table shows the average values of $m_{c o n}, \mathrm{~g}, \Delta \Theta_{w},{ }^{\circ} \mathrm{C}$, and $V_{g w v}, \mathrm{~m}^{3}$, obtained from the results of the study of 5 test gas samples. 
After processing the experimental data, the following result of measuring the net volume-basis specific calorific value of the studied natural gas was obtained:

$$
\begin{gathered}
\left(H_{V}\right)_{N}=(34.65 \pm 0.35) \mathrm{MJ} / \mathrm{m}^{3} ; U_{p}\left\{\left(H_{V}\right)_{N}\right\}= \\
=0.35 \mathrm{MJ} / \mathrm{m}^{3} ; p=0.95 ; k_{p}=1.96 .
\end{gathered}
$$

\section{Conclusions}

1. The calorimetric method provides precise and valid results of measuring the gross and net volumebasis-specific calorific values of natural gas in modern gasometry.

2. The methodology of estimating the accuracy of measuring the gross and net volume-basis-specific calorific values of natural gas by the developed calorimetric method, based on computing uncertainty of the measurement results by assessing both random and systematic impact factors, fully meets the requirements in ensuring the measurements unity; it can be recommended to apply in gasometry.

\section{Gratitude}

The authors express their gratitude to the members of the scientific seminar of the Department of Information and Measuring Technologies of Lviv Polytechnic National University for an interesting and meaninful discussion on the results of the studies.

\section{Conflict of interest}

The authors state that there are no financial or other potential conflicts regarding this work.

\section{References}

[1] V. Motalo, B. Stadnyk, A. Motalo, "Evaluation of Natural Gas Quality by its Calorific Value", Measuring Equipment and Metrology, vol.82, no.1, p.30-36, 2021, [Online], Available: https://doi.org/10.23939/istcmtm2021.01.030

[2] V. Motalo, B. Stadnyk, A. Motalo, I. Likhnovsky, "Hydrocarbon Gases Quality: Impact on Sustainable Development Goals and Environment", in Sustainable Production: Novel Trends in Energy, Environment and Material Systems, G.M. Krolczyk, and others, Eds. Part 8, Springer, p.105-129, 2020.[Online], Available: https://www.springer.com/us/book/ 9783030112738

[3] ISO 13686:2013 Natural gas: Quality designation. Reviewed and confirmed in 2020. - ISO, 2013.

[4] ISO 13443:1996 Natural gas: Standard reference conditions. - Reviewed and confirmed in 2020. - ISO, 1996.

[5] ISO 14532:2014 Natural gas: Vocabulary. Reviewed and confirmed in 2020. - ISO, 2014.
[6] P. Ulbig, D. Hoburg, "Determination of the calorific value of natural gas by different methods", Thermochimica Acta 382(1):27-35, vol.382, no.1-2, p. 27-35, 2002, [Online], Available: https://doi.org/10.1016/S0040-6031(01)00732-8

[7] C. Villermaux, M. Zarea1, F. Haloua, B. Hay, J.-R. Filtz, "Measurement of Gas Calorific Value: A New Frontier to be Reached with an Optimized Reference Gas Calorimeter", in Proc. 23rd World Gas Conference, Amsterdam, 2006. [Online], Available: http://members.igu.org/html/wgc2006/pdf/paper/add 12646.pdf

[8] J. Markowski, P. Imilkowski, M. Nowacki, D. Olejniczak, J. Madry, K. Netter, R. Jesionek, G. Wieczorkiewicz, "The concept of measurement of calorific value of gaseous fuels", in Proc. E3S Web of Conferences 207, 010 PEPM'2020, 25, 2020. [Online], Available: https://doi.org/ $10.1051 / \mathrm{e} 3$ sconf $/ 202020701025$

[9] A. Zajc, T. Ryll, "Rapid determination of the calorific value by means of a novel gas quality sensor", Measuring \& Process Control Reports, 2017-01-Heat Processing, 2017. [Online], Available: https://www.meterq.de/assets/ images/downloads/2017-01-Heat\%20Processing.pdf

[10] R. Hamaguchi, "Natural Gas Measurement Using Temperature-Dependent Thermal Conductivity", Technical Review 2018 - Azbil Corporation, 2018. [Online], Available: https://www.azbil.com/corporate/technology/review/pdf/rev2018E _.pdf

[11] ISO 15112:2018 Natural gas: Energy determination, 2018

[12] ISO 6974-1:2012 Natural gas: Determination of composition and associated uncertainty by gas chromatography, Part 1: General guidelines and calculation of composition. - Reviewed and confirmed in 2018. 2012.

[13] ISO 6976:2016 Natural gas: Calculation of calorific values, density, relative density and Wobbe index from composition. - ISO, 2016.

[14] ISO 15971:2008 Natural gas: Measurement of properties. Calorific value and Wobbe index. - Reviewed and confirmed in 2020: - ISO, 2013. [Online], Available: https://www.iso.org/standard/44867.html

[15] ASTM D1826-94 Standard Test Method for Calorific (Heating) Value of Gases in Natural Gas Range by Continuous Recording Calorimeter, ASTM International, West Conshohocken, PA, 2017. [Online], Available: www.astm.org DOI: $10.1520 / \mathrm{D} 1826-94 \mathrm{R} 17$

[16] GOST 27193-86. Natural combustible gases: Method for determination of calorific value with water calorimeter. - Reviewed and confirmed in 2021 (in Russian). [Online], Available: https://files.stroyinf.ru/Index2/1/4294827/ 4294827433.htm

[17] ISO/IEC 17025:2017, General Requirements for the Competence of Testing and Calibration Laboratories, 2017. ISO, 2017.

[18] ISO/IEC Guide 98-3:2008, Uncertainty of measurement, Part 3: Guide to the expression of uncertainty in measurement, 2008.

[19] EA-4/02 M: 2013, Expression of the Uncertainty of Measurement in Calibration: European Accreditation, 2013. 